\title{
Recherches actuelles menées en Chine sur la Révolution française
}

\section{Zhou Lihong}

\section{(2) OpenEdition \\ 1 Journals}

\section{Édition électronique}

URL : https://journals.openedition.org/ahrf/8333

DOI : 10.4000/ahrf.8333

ISSN : 1952-403X

Éditeur :

Armand Colin, Société des études robespierristes

\section{Édition imprimée}

Date de publication : 1 mars 2007

Pagination : 145-156

ISSN : 0003-4436

\section{Référence électronique}

Zhou Lihong, "Recherches actuelles menées en Chine sur la Révolution française », Annales

historiques de la Révolution française [En ligne], 347 | janvier-mars 2007, mis en ligne le 01 mars 2010,

consulté le 24 avril 2022. URL : http://journals.openedition.org/ahrf/8333 ; DOI : https://doi.org/

10.4000/ahrf.8333

Ce document a été généré automatiquement le 24 avril 2022.

Tous droits réservés 


\title{
Recherches actuelles menées en Chine sur la Révolution française
}

\author{
Zhou Lihong
}

\section{NOTE DE L'ÉDITEUR}

Je tiens à remercier ici le professeur Gao Yi pour ses précieux conseils et les encouragements donnés pour cet article. Mes remerciements s'adressent également, pour leur patience et les corrections de l'expression française apportées à ce texte, à mesdames Luisella Simpson et Anne Lecoq, ainsi qu'à monsieur Michel Biard, directeur des AHRF.

1 Il y a actuellement en Chine plus de vingt professeurs et doctorants qui travaillent sur la Révolution française à l'Université de Pékin, l'Université normale supérieure de Pékin, l'Université normale supérieure de Shanghai, l'Université normale supérieure de la capitale, et d'autres encore. L'Université de Pékin est au centre de ces recherches, sous la conduite du professeur Gao Yi. Au cours de ces dernières années, celui-ci a formé quatre doctorants et neuf étudiants de maîtrise, dont la plupart donnent des cours sur la Révolution française et étudient ce sujet dans des universités chinoises. À présent, sept doctorants et trois étudiants de maîtrise travaillent aussi sur la Révolution française sous la direction du professeur Gao Yi.

Ces recherches sur la Révolution française sont menées dans une ambiance ouverte de travail. Cette tradition remonte à 1979, année où la Révolution culturelle se termine en Chine et où Liu Zongxu publie un article intitulé "Sur la nature de la Réaction thermidorienne » dans la revue Études historiques, la meilleure revue d'histoire du pays. Liu Zongxu soutenait que la "réaction thermidorienne "fut" un moyen exceptionnel de mettre un terme au règne des Jacobins et un tournant pour établir l'ordre normal du capitalisme ", ce qui renversa en Chine la vision traditionnelle d'un tournant compris comme une simple contre-révolution. Par ailleurs, Liu Zongxu soutenait qu'être pour ou contre le système capitaliste est le critère pour juger si un événement est ou n'est 
pas révolutionnaire. Plus tard, cet auteur développa son point de vue jusqu'à établir la théorie du critère des forces productives ${ }^{1}$, qui passa dans les manuels de lycée et d'université, et qui exerça une grande influence sur la jeune génération. Les chercheurs chinois profitèrent de l'occasion ainsi offerte de réévaluer "la réaction thermidorienne " pour sortir de la prison des dogmes, dont celui du «principe directeur de la lutte des classes ». De plus, ils commencèrent à réévaluer les partis, les personnages et les événements de la Révolution française, et à réfléchir sur la classification des périodes de cette Révolution.

En même temps, avec le précieux appui du professeur Zhang Zhilian, les historiens chinois de la Révolution française élargissaient les échanges avec leurs collègues de France, des États-Unis, d'Angleterre et d'autres pays encore. C'est dans ce contexte particulier que les chercheurs chinois étendirent leur champ de vision et attachèrent de l'importance aux expériences du système politique et de la culture politique que la Révolution française a fournis au monde entier. Gao Yi, le plus remarquable chercheur de ce courant, a ainsi tout à la fois assimilé les expériences et critiqué les théories de la culture politique de François Furet, Michel Vovelle et Lynn Hunt. Dans Le Style français : la culture politique de la Révolution française (Éditions du peuple de Zhe Jiang, 1991), il a unifié de manière dialectique les relations entre la longue et la courte durée, entre la culture des élites et celle du peuple, entre la culture bourgeoise et la culture populaire ; et il a relu la Révolution française sous l'angle de la culture politique. La Révolution française, d'après lui, a inventé un "style politique de la lutte civile » et fourni un nouveau style de culture politique au monde entier.

4 Pour présenter les recherches menées sur la Révolution française en Chine, dans les cinq dernières années, j'insisterai sur trois aspects : les recherches sur les significations de la Révolution française ; les recherches sur les origines de la Révolution française ; les réflexions sur la culture révolutionnaire française.

Les recherches sur les significations de la Révolution française

5 Gao Yi a poursuivi la recherche sur les fonctions de la Révolution française pour son cours sur la démocratisation dans le monde. Dans un article intitulé « La position de la Révolution française dans le mouvement de démocratisation moderne de la politique ", présenté à la session annuelle sur l'histoire française (décembre 2002), il a affirmé que "la Révolution française a été une borne qui fait époque dans l'histoire de l'évolution de la politique mondiale, et a marqué l'ouverture de la tendance à la démocratisation de la politique cosmopolite, qui a contribué extraordinairement à l'invention du système moderne de la politique démocratique; ses expériences politiques, tant positives que négatives, sont une richesse spirituelle extraordinaire pour la politique démocratique $\mathrm{du}$ genre humain moderne. La Révolution française a facilité l'universalisation des valeurs de la démocratie et a été un grand service. Par contre, ses expériences historiques manifestent l'importance de la liberté individuelle».

6 Peu après, un autre chercheur, Liu Daming, a publié un livre intitulé L'Espoir de la régénération de la nation: l'éducation civique pendant la Révolution française (Éditions des sciences sociales de la Chine, 2005), ouvrage fondé sur sa thèse de doctorat sous la direction du professeur Gao Yi. Il a montré que l'éducation civique, qui est un instrument important pour réaliser la régénération de la Nation, contenait tous les aspects de la culture politique et de la vie religieuse de la France. L'éducation civique de la Révolution française a promu l'évolution de la civilisation occidentale et est devenue une des sources principales de la démocratisation de la politique moderne dans le 
monde. Pour sa part, Xin Yanhuai a publié un article intitulé «La transformation de l'éducation supérieure durant la Révolution française » (Revue Académique de l'Université normale supérieure de Hebei, 2004, $n^{\circ} 3$ ), qui étudie cette évolution et son influence sur la science au cours de la Révolution.

7 Les tentatives d'élaboration de constitutions ont également intéressé certains chercheurs chinois. Ainsi, Wang Yanping travaille-t-il en ce moment à une thèse de doctorat sous la direction du professeur Gao Yi. Il cherche à étudier le processus de préparation, d'établissement et d'application de la Constitution de 1791. Il met l'accent sur la fonction de la Constitution de 1791 en tant qu'outil de la Révolution. Par ailleurs, Shi Tongbiao, un chercheur dans le domaine du droit, a publié un livre intitulé $L a$ recherche sur la théorie du gouvernement constitutionnel et sa pratique pendant la Révolution française (1789-1814) (Éditions de l'Université du peuple de la Chine, 2004). Dans cet ouvrage, il a analysé systématiquement la culture du gouvernement constitutionnel à l'époque de la Révolution française. Il en tire trois leçons importantes : premièrement, les révolutionnaires n'ont pas établi véritablement un système de défense de la liberté individuelle; de plus, le manque d'organisme constitutionnel indépendant, du droit de recours et d'autorité judiciaire pour équilibrer le pouvoir législatif a conduit au mépris de la vie. Deuxièmement, on a appliqué d'infinies variantes de systèmes de contrôle démocratique, par exemple le vote par appel nominal, le vote par applaudissements, ou le peuple assistant comme simple auditeur ou observateur aux débats de l'Assemblée, ce qui a abouti à une "démocratie désordonnée ». Troisièmement, le manque de la culture du contact et l'idée qu'aucune constitution ne puisse restreindre la souveraineté du peuple ont engendré le changement fréquent de constitution. Dans un article sur « La vie quotidienne et la vie publique : un cas de stabilité de la loi civile et de changement de la constitution pendant la Révolution française » (Salle d'Étude, 2002, $\mathrm{n}^{\circ}$ 6), un autre chercheur, Liu Cheng, a montré que la stabilité de la loi civile et le changement de constitution pendant la Révolution française reflétaient la différence de ces deux styles de vie sous ces deux systèmes de loi. Cependant, la promulgation du Code Napoléon marqua un retour de la vie publique à la vie quotidienne et une transformation de la période agitée en une période d'accalmie.

8 La famille pendant la Révolution française est également un sujet qui a beaucoup attiré les chercheurs chinois. Dans son article sur « La Réforme de la législation familiale et la pratique révolutionnaire des femmes: de l'importance du principe de "liberté et égalité " de la Révolution française pour le féminisme » (Clio At Beida, n 7, Éditions de l'Université de Pékin, 2000), Li Ji remarque que le principe « liberté et égalité », promu par la Révolution française, fut en réalité très limité dans la pratique. Toutefois, ce principe offrit aux femmes un contexte favorable à la réflexion sur leur rôle et leur position historique, ce qui favorisa le développement du féminisme archaïque. Dans son article «Le débat sur la recherche de paternité naturelle pour des enfants illégitimes pendant la Révolution française » (Revue mensuelle d'histoire, 2003, $\mathrm{n}^{\circ}$ 6), Long Hongpu a, quant à lui, étudié le processus de la suppression de la recherche de paternité naturelle au nom de la défense des droits du père légitime et de la propriété pendant la Révolution française.

9 À partir d'un article de Xu Hong, publié sous le titre "La nouvelle recherche sur les causes des révoltes des paysans de Vendée en France en 1793 ", Zhu Aiqing et Liu Beicheng ont publié un article intitulé "Le commentaire sur "la révolte de Vendée" " (Revue mensuelle d'histoire, 2004, $\mathrm{n}^{\circ} 7$ ). Ces deux auteurs pensent qu'on ne 
peut pas attribuer la révolte de Vendée à «l'ignorance » et au «conservatisme » des paysans. Pour eux, la révolte est due à la contradiction entre la politique du gouvernement républicain et le sentiment traditionnel des paysans. De plus, ils ont remarqué que les conflits entre les paysans ou les groupes inférieurs de la société luttant pour leur intérêt personnel, et le gouvernement qui prend en main le pouvoir discursif de "révolution", sont fréquents dans les processus de révolution ou de modernisation. Il est intéressant de noter, enfin, que Shi Zhan, doctorant du professeur Gao Yi, et Zhang Zhi, doctorant du professeur Li Hongtu (Université normale supérieure de Shanghai) ont choisi Joseph de Maistre comme sujet de thèse de doctorat. Zhang Zhi cherche à étudier l'avis de Maistre sur la Révolution française du point de vue de la sauvagerie et de la civilisation. De plus, il voudrait montrer l'influence du couple de notions «sauvagerie et civilisation»dans la construction de la société et du gouvernement.

Dans un autre article, intitulé "Sur la politique agricole et industrielle sous la monarchie, une recherche sur les réformes au début de la Révolution française » (Les problèmes d'enseignement en histoire, 2004, $\mathrm{n}^{\circ} 4$ ), Wang Ling Yu a étudié une série de réformes concernant la libéralisation de l'économie, par exemple, en matière agricole, la suppression des droits féodaux, la redistribution des terres et l'établissement du nouveau système de propriété; en matière industrielle, la suppression des corporations, jurandes et maîtrises, la proclamation de la loi Le Chapelier, et le remplacement des règlements désuets qui ont embarrassé le développement de l'industrie. Pour sa part, Dong Yanshou a étudié les clubs pendant la Révolution française ("Sur les clubs pendant la Révolution française», Revue Académique de l'Université de Henan, 2000, n 3) et souligné, d'une part, que les clubs sont l'appui et le moteur de la Révolution, et, d'autre part, que la différenciation des clubs reflétait le changement des factions révolutionnaires et l'évolution de la Révolution.

11 Un autre chercheur, Gao Yunqing, a noté dans un article paru sous le titre « La Fayette dans la Révolution française " (Bulletin académique de l'Université des affaires étrangères, $\left.2000, n^{\circ} 3\right)$ qu'on devait confirmer la proposition politique de La Fayette puisqu'elle s'accorda non seulement avec la revendication de la grande bourgeoisie, de la moyenne bourgeoisie, de la petite bourgeoisie, mais aussi avec le peuple et le niveau du développement social et économique. Li Hongtu a, de son côté, remarqué dans son article «Louis XVI : un réformateur dramatique » (Exploration et débat, 2004, $\mathrm{n}^{\circ} 7$ ) que, contrairement à l'image du monarque despotique et du roi serrurier qui s'était imposée en Chine depuis longtemps, Louis XVI était en fait un réformateur ambitieux et qu'il est devenu la victime de la Révolution à cause du retournement de la situation. Les travaux de Li Hongtu permettent ainsi, en Chine, de redécouvrir la figure de Louis XVI de manière plus large.

12 Par ailleurs, certains chercheurs venus d'autres milieux ont étudié la Révolution française sous différents aspects. Fang Renjie a suggéré dans un article intitulé «La recherche sur les caractéristiques des langues, avant et après la Révolution française " (La langue étrangère et l'enseignement de la langue étrangère, 2002, $\mathrm{n}^{\circ} 8$ ) que la Révolution bourgeoise avait renversé la domination de la langue des nobles et établi la position de la langue romantique de la bourgeoisie. Cependant, il pense que ces deux langues ont puisé leur source dans la langue populaire, et que l'évolution a concerné seulement les termes et la façon de parler, mais non le vocabulaire élémentaire et la grammaire. Zhou Qing a, pour sa part, analysé trois romans A Tale of Two Cities, Quatre-vingt-treize et Les 
dieux ont soif, dans son article «La recherche sur les pensées humanitaires de la littérature concernant la Révolution française " (Revue académique de l'Université de Jiangnan, 2002, $\mathrm{n}^{\circ} 1$ ). Il pense que les attaques de la tyrannie et le déni de la violence révolutionnaire de ces trois romans proviennent des pensées humanitaires dont le noyau est la bonté. Enfin, un autre chercheur, Han Le, a remarqué dans un article ( La recherche sur l'opéra salvateur pendant la Révolution française ", Revue académique de l'Université de Yun Cheng, 2005, $n^{\circ}$ 4) que « l'opéra salvateur » joué pendant la Révolution française avait fonctionné comme un outil de propagande politique, mais qu'il avait eu des limites artistiques. D'après Han Le, la disparition de «l'opéra salvateur » démontre que la valeur artistique contribue à la popularisation de l'opéra. En somme, les recherches en dehors du domaine de l'histoire nous ont montré les différents aspects de la Révolution française; toutefois, les auteurs ne connaissent pas bien le contexte historique, c'est pourquoi ils ne peuvent pas analyser les sujets complètement.

Les recherches sur les origines de la Révolution française

Les origines de la Révolution française sont un sujet qui a traditionnellement attiré les chercheurs chinois, et ce depuis longtemps. Dans l'article publié sous le titre "Les pensées de Mably et la Révolution française " (Revue académique de l'Université normale supérieure de Shanghai, 2002, n 3), Chen Chongwu a ainsi étudié l'influence de Mably sur les différentes étapes et les personnages représentatifs de la Révolution française du point de vue des pensées elles-mêmes, de leur position historique et de leur fonction. Il a confirmé l'appellation donnée à Mably : « le père de la Révolution française ». Pour sa part, Liu Beicheng, dans un article intitulé «L'interprétation de Tocqueville sur les causes de la Révolution française " (Revue académique de l'Université normale supérieure de Pékin, 2001, $\mathrm{n}^{\circ}$ 3), a étudié les rapports paradoxaux entre le développement économique, la transformation politique et la Révolution. Il a confirmé la thèse de Tocqueville, selon laquelle "l'irruption de la Révolution ne peut pas être attribuée à une dégradation de la situation du peuple ». Un autre chercheur, Chong Ming, a, lui, étudié les travaux de Tocqueville sur la tradition de la Révolution ( «Les recherches de Tocqueville sur la tradition de la Révolution française ", article paru dans Clio At Beida, $\mathrm{n}^{\circ}$ 10, Éditions de l'Université de Pékin, 2004). Il a mis l'accent sur le fait que, chez Tocqueville, la tradition de la Révolution et l'autocratie en France proviendraient du dépouillement de la liberté politique nationale et de la vie politique par l'État à l'époque de l'Ancien Régime, à travers la centralisation du pouvoir. Enfin, dans un article consacré à " La recherche sur l'historiographie du révisionnisme sur les origines de la Révolution", Hong Qingming a présenté systématiquement les recherches des historiens du "révisionnisme » sur les origines de la Révolution du milieu des années 1950 aux années 1990.

14 Les progrès des recherches sur des sujets concrets sont également brillants. Ils sont reflétés par une série de thèses de doctorat et de mémoires de maîtrise sous la direction du professeur Gao Yi. Dans le mémoire intitulé Le Parlement de Paris et l'évolution de la culture politique française au XVIII siècle (publié dans Studies on Hellenic and Western Civilization, $\mathrm{n}^{\circ} 1$, Éditions de ShangWu, 2003), Pang Guanqun a démêlé les luttes entre le Parlement de Paris et les droits régaliens et a révélé le rapport entre le Parlement de Paris et l'évolution de la culture politique française au XVIII ${ }^{e}$ siècle. Elle a remarqué que, d'un côté, le Parlement de Paris continuait la tradition politique depuis le Moyen Âge ; de l'autre, qu'il a bien profité de l'opinion publique, conçue comme une sorte de nouveau tribunal à même de juger la politique, et qu'il a présenté certaines pensées modernes, puis est arrivé à certaines conclusions radicales ayant accéléré la chute de la 
monarchie absolutiste. De son côté, Li Ji a étudié la vie de Malesherbes et a expliqué en détail l'évolution des pensées philosophiques et de la culture politique à la fin de l'Ancien Régime (dans un mémoire soutenu sous le titre suivant: Malesherbes et le déclin de l'Ancien Régime en France). Dans son mémoire, Liqian a abordé, pour sa part, les pensées politiques et les activités principales du comte de Clermont-Tonnerre, le représentant des nobles libéraux, et a révélé les raisons profondes du déclin des nobles libéraux avec la monarchie.

Pang Guanqun a, quant à elle, soutenu avec succès en juin 2005 sa thèse de doctorat sous le titre La réforme de Maupeou : le tournant de la politique à la fin de l'Ancien Régime. Elle a réfléchi à l'importance fondamentale de la réforme de Maupeou dans les luttes entre le Parlement de Paris et les droits régaliens depuis le milieu du XVIII ${ }^{\mathrm{e}}$ siècle, et étudié cette réforme dans les domaines politique, économique, judiciaire et religieux. De plus, elle a souligné comment cette réforme, en visant à sauver la monarchie, avait finalement contribué à accélérer sa chute. De son côté, un autre chercheur, Huang Yanhong, travaille à une thèse sur la recette du fisc et le privilège de l'Ancien Régime en France. Il cherche à étudier les obstacles que le gouvernement a rencontrés en matière de la réalisation de l'égalité de la recette du fisc, pour expliquer le conflit entre la rationalisation de l'État et le système social ainsi que les mentalités culturelles. Il voudrait finalement expliquer les défauts fondamentaux de l'Ancien Régime et les origines de la Révolution. Pour sa part, choisissant Mlle de Lespinasse, une femme de salon, comme un cas de sa thèse, Zhao Yibin cherche à donner une vision des mœurs et des mentalités sociales combinant la raison et la sensibilité des Lumières du point de vue des rapports entre les femmes et l'histoire de la conversation, les activités sociales des Lumières et la sphère publique. Enfin, Zhou Lihong, travaille, quant à elle, à une thèse sur les réformes de la libéralisation du commerce des grains depuis le contrôleur général Bertin jusqu'à Turgot. Elle pense que ces réformes sont une voie pour amorcer un changement par le haut, en utilisant la liberté du commerce des grains pour résoudre la crise difficile rencontrée par la monarchie ; mais que, à terme, l'échec de la réforme de Turgot conduit à la Révolution et donc au changement venu d'en bas.

Les réflexions sur la culture révolutionnaire française

16 Ayant publié en 1991 Le Style français : la culture politique de la Révolution française, Gao Yi continue à approfondir ses réflexions sur la culture révolutionnaire française. Son article récent «Sur le désenchantement de la société sous la Réaction thermidorienne " (Studies On Hellenic And Western Civilization, $n^{\circ}$ 1, Éditions de ShangWu, 2003) analyse les manifestations du désenchantement social : les classes possédantes se réjouissaient fanatiquement, buvaient trop et donnaient libre cours à leur joie. Gao Yi a montré comment cette "grande réaction de la culture sociale » avait nié foncièrement le rêve d'une sous-culture politique des Jacobins/sans-culottes (celle de former les hommes nouveaux du républicanisme) et avait reflété la nature illusoire de la "conviction de rupture» qui se trouvait au cœur de la culture révolutionnaire française. De plus, d'après Gao Yi, ce désenchantement montrerait que la Révolution française fut une révolution bourgeoise. Pendant cette période, n'importe quelle force non capitaliste cherchant à réaliser son rêve social et politique ne pouvait que réussir de manière éphémère, tout au plus.

17 La culture politique, qui prit une couleur radicale d'exception, contribua à modeler les mentalités du «culte de la révolution » en Chine depuis le début du XX $\mathrm{X}^{\mathrm{e}}$ siècle. Cela influença dans une large mesure la vie politique en Chine, laquelle fut partagée entre 
joie et peine pendant un siècle. Dans une communication intitulée "Analyses sur l'interaction culturelle entre la Chine et la France au cours de la modernisation politique $»^{2}$, présentée au «Forum de Beida » en 2002, Gao Yi a exposé et prouvé la grande influence de la culture révolutionnaire française sur les origines de la révolution chinoise $\mathrm{du} \mathrm{XX}^{\mathrm{e}}$ siècle. Il estime que, dans la période où se prépara la révolution de Xinhai, l'utilisation par les révolutionnaires chinois d'une propagande autour de la Révolution française a eu un certain caractère d'" acculturation ", c'est-àdire qu'elle combina des facteurs de la culture révolutionnaire française avec des formes d'action et de systèmes de valeurs immanents, inhérents à la nation chinoise, lesquels ont abouti graduellement à la conviction que la révolution radicale était le seul moyen de sauvegarder la nation, et à une mentalité durable du «culte de la révolution ".

Depuis les années 1980, les intellectuels chinois ont commencé à réfléchir sur le concept même du «culte de la révolution » qui avait pris de l'ampleur pendant la Révolution culturelle chinoise. En 1995, Li Zehou et Liu Zaifu ont proposé de faire ce qu'ils nomment des "adieux à la révolution ». Ils affirmaient que la révolution, de gauche ou de droite, mène à la catastrophe. Il fallait donc dire adieu à la révolution qui renverse le système existant et l'autorité existante par la violence populaire. Cette opinion allait au devant des désirs de certains intellectuels : c'est pourquoi l'idée de liquider la révolution est devenue à terme un véritable courant de pensée. Certains chercheurs comparèrent alors la Révolution française à la Révolution culturelle chinoise, en ce que la révolution était associée à la violence. Ils affichèrent leur préférence pour les révolutions anglaise et américaine, au nom de la soi-disant « justice de la procédure ».

19 Aussi, depuis quelques années, des versions en chinois de Sister Revolution par Susan Dunn, des Souvenirs d'Alexis de Tocqueville, des Lectures on the French Revolution par E. E. D. Acton, et de Penser la Révolution française par François Furet ont été publiées successivement et nourrissent les réflexions sur la Révolution. Qiufeng, le traducteur des Lectures on the French Revolution, a ainsi critiqué violemment la Révolution française dans sa postface. Il estime que, combinant la révolution politique et sociale, elle a dédaigné la liberté personnelle et a provoqué des conséquences catastrophiques. En revanche, il loue les révolutions anglaise et américaine qui ne concernent que la révolution de la structure politique. Cette opinion est un développement du courant de pensée de l'« adieu à la révolution ». Même si les chercheurs chinois ont par ailleurs publié certains articles pour présenter l'historiographie «révisionniste» sur la Révolution française, la version en chinois du Penser la Révolution française de François Furet (Libraire de San Lian, 2005) est désormais le premier livre « révisionniste » publié en Chine. De ce fait, François Furet est devenu à la mode dans les milieux intellectuels.

20 Toutefois, le courant de pensée qui dénonce toute révolution, surtout la Révolution française, a suscité certaines réactions critiques parmi les chercheurs historiens. Par exemple, Huang Wansheng, un chercheur chinois qui réside à l'étranger, a critiqué sévèrement le courant de pensée des "adieux à la révolution " dans sa préface à la version chinoise de Penser la Révolution française. Il affirme en effet que la révolution est un moyen de défendre le droit à l'égalité et à la justice sociale, qu'elle a une légitimité de fond et qu'on ne peut la refuser dans aucun cas.

21 Par ailleurs, en 2005, afin d'équilibrer le courant de pensée conservateur de la contrerévolution, le professeur Gao Yi a invité le professeur Claude Mazauric à donner une 
série de conférences à l'Université de Pékin. Celui-ci y a démontré que l'historiographie de la "contre-révolution", apparue à l'époque de la guerre froide et celle des "néolibéraux ", surgie après la guerre froide, s'opposent en fait à l'historiographie du libéralisme apparue sous la Restauration, qui, elle, respecta pourtant les faits objectifs. Aussi, cette historiographie de la " contre-révolution » aussi bien que l'historiographie des "néo-libéraux» reflètent-elles un sentiment nostalgique, lointain héritier de Burke, démodé depuis longtemps, ainsi qu'une tendance antiscientifique qui simplifie les phénomènes complexes de la Révolution française. De plus, Claude Mazauric a souligné que l'historiographie "classique » de la Révolution française n'est certes pas détruite par cette tendance, mais qu'elle montre bien au contraire une nouvelle vigueur et jeunesse à travers les efforts d'historiens tel que Michel Vovelle, et qu'en outre, elle a reçu l'approbation d'historiens dans le monde entier. Cette mise au point présentée par Claude Mazauric a donc contribué fortement à l'approfondissement des réflexions des milieux de la recherche chinois sur la Révolution française et son importance dans la culture politique.

En conclusion, on peut ainsi constater qu'il y a des particularités certaines dans les recherches sur la Révolution française menées en Chine depuis cinq ans. Premièrement, certains chercheurs ont élargi leur champ de vision; par exemple, ils ont approfondi les recherches sur la culture politique. D'autres chercheurs s'intéressent aux phénomènes de la contre-révolution à l'époque de la Révolution qui avaient été longtemps ignorés en Chine. Ils cherchent à étudier les connotations profondes des phénomènes sous différents angles pour révéler la complexité de la progression de la civilisation. En même temps, les recherches sur les salons et la presse ont été renforcées pour étudier les origines de la Révolution française sous plusieurs aspects. Deuxièmement, les chercheurs ont commencé à choisir des sujets plus particuliers, par exemple la recherche sur la réforme de Maupeou par Pang Guanqun, la recherche sur les réformes de la libéralisation du commerce des grains de 1763 à 1776 par Zhou Lihong, ou encore la recherche sur la Constitution de 1791 par Wang Yanping. Troisièmement, les chercheurs ont utilisé beaucoup plus de documents qu'auparavant.

Dans une large mesure, on peut attribuer ces changements aux bons échanges entre les milieux de la recherche sur la Révolution française de la Chine et des pays étrangers, surtout ceux de la France. D'une part, de grands spécialistes de la Révolution française, tels que Colin Lucas, Timothy Tackett, Jean-Clément Martin et Claude Mazauric, sont venus tour à tour en Chine pour y donner des conférences. D'autre part, les grands spécialistes chinois de la Révolution française, comme Zhang Zhilian et Gao Yi, ont participé fréquemment aux conférences internationales et ont fait des séjours de recherche en France. Du 29 septembre au 2 octobre 2003, Gao Yi, Duan Mumei, Lou Junxin, Shen Jian, Li Hongtu et Wang Lingyu ont participé à des échanges de recherche en France à l'invitation de l'IHRF et du Musée de la Révolution française de Vizille. Ils ont donné en France une série de conférences sur la Révolution française dans le séminaire de DEA dirigé par le professeur Jean-Clément Martin à l'Université Paris I et lors des journées d'études franco-chinoises au musée de la Révolution française à Vizille. Par ailleurs, les doctorants ont eu la possibilité de passer quelques mois en France où ils ont pu rassembler une masse importante de documents et discuter avec des spécialistes de leur domaine de recherche, ce qui a beaucoup amélioré la qualité des thèses de doctorat. Monsieur Jean-Luc Domenach, directeur de l'Antenne Pékin, monsieur Jean-Clément Martin, directeur de l'IHRF (Université Paris I) et monsieur Claude Mazauric, professeur émérite à l'Université de Rouen ont également apporté 
leur brillante contribution aux doctorants chinois spécialisés sur la Révolution française. Depuis la fondation de l'Antenne Pékin en 2002, monsieur Jean-Luc Domenach prend à cœur les recherches sur la Révolution française menées en Chine et a envoyé un certain nombre de doctorants faire un stage de recherche en France; monsieur Jean-Clément Martin a chaleureusement reçu ces doctorants chinois à l'IHRF et leur a procuré des facilités pour leurs recherches. Enfin, monsieur Claude Mazauric et monsieur Michel Biard, professeur à l'Université de Rouen, ont, tous deux, envoyé aux doctorants de l'Université de Pékin beaucoup d'ouvrages correspondant à leurs sujets de thèse et ont fait un grand effort pour établir des liens entre les chercheurs de l'Université de Rouen et ceux de l'Université de Pékin.

Nous apprécions les succès ainsi obtenus, mais, en même temps, nous connaissons hélas les handicaps qui gênent les recherches sur la Révolution française et il convient de les rappeler ici. Tout d'abord, la base des recherches est encore faible et beaucoup de domaines de recherche restent à approfondir. Ensuite, le groupe de recherche n'est pas assez important pour nourrir suffisamment des échanges entre ses différents centres, y compris à l'intérieur de la Chine. Enfin, les chercheurs chinois n'ont pas assez de moyens pour aller travailler dans les archives françaises sur des sujets nouveaux et particuliers. Il va donc de soi que l'avenir des recherches sur la Révolution française menées en Chine dépend ainsi de l'aplanissement de ces obstacles.

\section{NOTES}

1.Selon la théorie du critère des forces productives de Liu Zongxu, d'une part, les forces productives sont le moteur de l'histoire, et on attribue les progrès de la civilisation anthropique au développement des forces productives; d'autre part, les forces productives sont le critère pour juger du phénomène historique. L'évolution et la réussite de la civilisation anthropique dépendent de son adaptation aux forces productives.

2.Cette communication est acceptée dans la collection de dissertations du «Forum de Beida » intitulée La Civilisation Anthropienne vers l'avenir : une observation du point de vue pluridisciplinaire, Éditions de l'Université de Pékin, 2003.

\section{AUTEUR}

\section{ZHOU LIHONG}

Doctorante de l'Université de Pékin 